\title{
Fungsi Dan Makna Simbolik Kesenian Jaranan Jur Ngasinan Desa Sukorejo Kecamatan Sutojayan Kabupaten Blitar
}

\author{
Dwi Zahrotul Mufrihah \\ Program Studi Pendikan Seni Budaya, Pascasarjana Universitas Negeri Surabaya
}

zahrotul1704@gmail.com

\begin{abstract}
Jaranan Jur Ngasinan merupakan kesenian yang tumbuh dan berkembang di Desa Sukorejo Kecamatan Sutojayan Kabupaten Blitar. Kesenian Jaranan Jur Ngasinan memiliki keunikan dalam hal fungsi yang disesuaikan dengan kepercayaan masyarakat pendukungnya. Berdasarkan latar belakang tersebut, peneliti mengajukan beberapa rumusan masalah yakni bagaimana fungsi dan makna yang terkandung dalam Kesenian Jaranan Jur Ngasinan Desa Sukorejo Kecamatan Sutojayan Kabupaten Blitar. Adapun tujuan khusus dari penelitian ini adalah untuk mendeskripsikan fungsi dan makna simbolik Kesenian Jur Ngasinan Desa Sukorejo Kecamatan Sutojayan Kabupaten Blitar. Data diperoleh peneliti dengan menggunakan pendekatan kualitatif studi kasus. Peneliti memfokuskan pada isu atau persoalan, kemudian memilih satu kasus terbatas untuk mengilustrasikan persoalan. Subjek pada penelitian ini Tari Tayung Raci, terdapat didalamnya yaitu isi kesenian dari pertunjukan dan pelaku seni. Hasil penelitian antara lain fungsi Jaranan Jur Ngasinan sebagai sarana ritual, presentasi estetis, sebagai pengikat solidaritas kelompok masyarakat, dan sebagai media pelestarian budaya. Kedua, makna kesenian Jaranan Jur Ngasinan Desa Sukorejo Kecamatan Sutojayan Kabupaten Blitar terdapat pada nama "Jur", gerak, musik, tata rias dan busana, property, dan pola lantai. Dari penjelasan itu dapat disimpulkan bahwa Jaranan Jur Ngasinan memiliki berbagai fungsi dan memiliki makna simbolik tentang prajurit yang juga terkait dengan nilai-nilai budaya masyarakat di sekitar sana.
\end{abstract}

Kata Kunci: Fungsi, Makna, Jaranan Jur Ngasinan, Kesenian Blitar

\section{The Function And Meaning Of Jaranan Jur Ngasinan Art Of Sukorejo Village, Sutojayan Subdistric, Blitar Regency}

Jaranan Jur Ngasinan is an art which grow and develop on Sukorejo village, Sutojayan sub-distric, Biltar regency. This art has uniqueness in function which compromise to supporting community's. Based on that background, the researcher make some research questions there are how are function and meaning which are contained in Jaranan Jur Ngasinan art, Sukorejo Village, Sutojoyan Subdistrict, Blitar Regency. There are special purposes from this research for described the function and symbolic meaning of Jaranan Jur Ngasinan art, Sukorejo Village, Sutojoyan Subdistrict, Blitar Regency. Data obtained by researcher by using qualitative approach of case study. Researchers focused on the issue, then choose one limited case to illustrate the issue. The subject of this research is the Tayung Raci Dance, which contains the contents of art from performers and performers of art The result which gained by researcher. First Jaranan Jur Ngasinan have function as ritual facility, presentation of the beauty, a fastener of solidarity community, and media cultural preservation. Second, meaning of Jaranan Jur Ngasinan Sukorejo Village, Sutojayan Subdistrict, Blitar Regency are an honest meaning which is come from the name "Jur", motion, music, makeup and clothes, property, and floor patterns. From that explanations can be concluded that Jaranan Jur Ngasinan have various function and have symbolic meaning about soldier which also related to values of society culture around there.

Keywords : Function, Meaning, Jaranan Jur Ngasinan, Blitar's art

Proses Review : 1 - 31 Maret 2018, Dinyatakan Lolos: 10 April 2018 


\section{PENDAHULUAN}

Kabupaten Blitar merupakan salah satu daerah di Provinsi Jawa Timur yang terletak dibagian selatan dengan memiliki 22 kecamatan. Salah satu dari 22 kecamatan di Kabupaten Blitar adalah Sutojayan yang sering disebut sebagai Lodoyo. Menurut Mardjuni di daerah ini memiliki kesenian yang menjadi ciri dan sebagai identitas Desa Sukorejo yaitu Jaranan Jur Ngasinan (Wawancara, 15 Oktober 2015). Hartono menambahkan bahwa Jaranan Jur Ngasinan berada di Desa Sukorejo Kecamatan Sutojayan merupakan salah satu kesenian tertua di Kabupaten Blitar (Wawancara, 04 Februari 2016). Awal kemunculan menurut Mardjuni pini sepuh dan pengendang Jaranan Jur Ngasinan pada tahun 1921. Terkait dengan hal itu perbedaan Jaranan Jur Ngasinan dengan Jaranan-jaranan di Kabupaten Blitar antara lain, 1) Jaranan Jur Ngasinan mempunyai bentuk penyajian masih "asli" tanpa ada pembaharuan dari awal muncul pada tahun 1921 hingga saat ini sesuai dengan nilai budaya masyarakat sekitar, 2) Jaranan Jur Ngasinan mempunyai fungsi selain sebagai "presentasi estetis" atau "tontonan" juga mempunyai fungsi sebagai ritual (Wawancara, 15 Oktober 2015). Masyarakat sekitar memiliki kepercayaan bahwa ketika mengadakan hajatan akan menampilkan Jaranan Jur Ngasinan sebagai "nadzar" rasa syukur kepada Tuhan Yang Maha Esa tetapi ketika "nadzar" tersebut tidak dilaksankan akan terjadi sebuah musibah.

Berdasarkan pemaparan tentang Jaranan Jur Ngasinan fenomena muncul dari fungsi jaranan yang sesuai dengan kepercayaan masyarakat pendukungnya. Pertunjukan Jaranan Jur Ngasinan menarik untuk diidentifikasi sebab pertunjukan Jaranan Jur Ngasinan menggambarkan tentang kegagahan prajurit berkuda selain itu memiliki makna tentang nilai budaya masyarakat. Akan tetapi, tidak banyak masyarakat di luar Kabupaten Blitar mengetahui bahwa di Kabupaten Blitar memiliki kesenian Jaranan yang unik. Untuk itu, peniliti tertarik menggunakan judul "Fungsi dan Makna Simbolik Jaranan Jur Ngasinan Desa Sukorejo Kecamatan Sutojayan Kabupaten Blitar".

Rumusan Masalah penelitian adalah bagaimana fungsi Kesenian Jaranan Jur Ngasinan Desa Sukorejo Kecamatan Sutojayan Kabupaten Blitar dan bagaimana makna simbolik pada Kesenian Jaranan Jur Ngasinan Desa Sukorejo Kecamatan Sutojayan Kabupaten Blitar. Tujuan Penelitian dibagi menjadi 2 yakni tujuan penelitian ini secara umum adalah untuk menganalisis Fungsi dan Makna Kesenian Jaranan Jur Ngasinan Desa Sukorejo Kecamatan Sutojayan Kabupaten Blitar. Tujuan khusus untuk mendeskripsikan fungsi Kesenian Jaranan Jur Ngasinan Desa Sukorejo Kecamatan Sutojayan Kabupaten Blitar dan untuk mendeskripsikan makna simbolik pada Kesenian Jaranan Jur Ngasinan Desa Sukorejo Kecamatan Sutojayan Kabupaten Blitar. Manfaat penelitian antara lain hasil penelitian ini dapat memberikan kontribusi terhadap pendokumen- tasian sehingga masyarakat juga mengenal kesenian tradisional, hasil dari penelitian ini dapat menambah bahan pustaka dalam perpustakaan baik di jurusan maupun di fakultas. Penelitian ini menggunakan beberapa landasan teori yang terkait dengan penelitian. Berikut pemaparan teori yang digunakan :

\section{Jaranan}

Jaranan berasal dari kata jaran yang berarti kuda. Jaranan merupakan tarian yang melukiskan gerak penunggang kuda. Para penari menaiki anyaman bambu berbentuk kuda seperti yang diungkapkan oleh Pigeaud (1991:21) menyatakan bahwa yang dimaksud dengan tari kuda adalah pertunjukan atau penampilan orang yang dengan mengepit anyaman yang dibuat dari bambu atau kulit, menirukan kuda atau penunggang kuda. Tari-tarian yang bersifat kerakyatan, termasuk jaranan telah berkembang dan merupakan pertunjukan yang cukup popular diseluruh pedesaan pada tahun 1930. Kelompok Jaranan sangat beragam menurut R. Djoko Prakoso (2006:13) terdapat 5 jenis di Jawa Timur. 1) Jaranan Jawa, 2) Jaranan Pegon 3) Jaranan Sentherewe, 4) Jaranan Breng, 5) Jaranan Buta atau Turangga Yakso.

\section{Fungsi Seni Pertunjukan}

Menurut Soedarsono dalam bukunya Seni Pertunjukan di Era Globalisasi (2002: 118) bahwa seni pertunjukan memiliki fungsi yang sangat kompleks dalam kehidupan manusia. Fungsi dikelompokkan menjadi dua yaitu kelompok fungsi primer dan sekunder. Kelompok fungsi primer dibagi menjadi tiga berdasarkan atas 'siapa' yang menjadi penikmat seni pertunjukan antara lain: (1) sebagai sarana ritual, (2) sebagai ungkapan atau hiburan pribadi, (3) Sebagai presentasi estetis. Fungsi Sekunder apabila seni pertunjukan bertujuan bukan untuk dinikmati, tetapi untuk kepentingan yang lain.

\section{Makna Simbolis}

Bentuk penyajian sebuah pertunjukan seni selalu mempunyai makna simbolis baik dari segi gerak, musik, tata rias busana, perlengkapan, dan properti. Seperti yang diungkapkan oleh Jacqueline Smith dalam buku Komposisi Tari: Sebuah Petunjuk Praktis Bagi Guru (1985: 29), bahwa istilah penyajian adalah simbol-simbol atau tanda dalam suatu pentas. Dalam buku Komposisi Tari: Sebuah Petunjuk Praktis Bagi Guru (1985: 29) dijelaskan bahwa simbol berasal dari kata Yunani yaitu "Symbolos" yang berarti tanda yang memberikan sesuatu kepada orang lain. Menurut Herusatoto (1983: 11-14), dengan demikian simbol merupakan bentuk lahiriah yang mengandung maksud, sedangkan makna adalah isinya.

\section{Bentuk Penyajian}

Bentuk penyajian menurut Sumandiyo Hadi (2003: 36) adalah wujud fisik yang menunjukkan suatu kesatuan integral yang terdiri atas beberapa komponen atau unsur yang saling berkaitan dan dapat dilihat atau dinikmati secara visual. Bentuk penyajian terdiri dari alur penyajian, gerak, musik, tata rias dan busana, tata cahaya, setting, property dan pelengkap lainnya. 


\section{Kesenian}

Kesenian dibagi menjadi dua menurut SD. Humardani dalam buku Seni Pertunjukan Etnik Jawa Ritus, Simbolisime, Politik, dan Problematikanya (2008: 89-90), yaitu kesenian rakyat dan kesenian istana. 1) Kesenian rakyat yang hidup dan berkembang dilingkungan pedesaan yang bersifat sederhana, spontan dan tidak resmi. 2) Kesenian istana (kraton) bersifat rumit, fomal, dan mendetail.

\section{Seni Pertunjukan}

Seni pertunjukan Indonesia menurut Edi Sedyawati (2002: 07) digolongkan ke dalam tiga tipologi berbeda. Tipologi pertama adalah tipologi berdasarkan artistik/keindahan, tipologi kedua yaitu dibuat berdasarkan fungsi sosial, tipologi ketiga yaitu didasarkan pada sebuah pertanyaan, apakah kesenian itu dramatisasi atau bukan.

\section{METODE}

Metode penelitian Creswell (2015) dibagi dalam lima pendekatan, antara lain pendekatan naratif, fenomenologi, grounded theory, etnografi, dan studi kasus. Penelitian ini menggunakan pendekatan kualitatif studi kasus. Penelitian studi kasus adalah pendekatan kualitatif yang penelitinya mengeksplorasi khidupan nyata, sistem terbatas kontemporer (kasus) atau beragam sistam terbatas (berbagai kasus), melalui pengumpulan data yang detail dan mendalam yang melibatkan beragam sumber informasi (misalnya, pengamatan, wawancara, baham audiovisual, dan dokumen dan berbagai laporan), dan melaporkan deskripsi kasus atau tema kasus (2015: 135-136).

Peneliti memfokuskan pada isu atau persoalan, kemudian memilih satu kasus terbatas untuk mengilustrasikan persoalan. Dengan pendekatan kualitatif studi kasus diharapkan hasil penelitian yang telah dilakukan dapat dipercaya dan bermanfaat.

Subjek pada penelitian ini Tari Tayung Raci, terdapat didalamnya yaitu isi kesenian dari pertunjukan dan pelaku seni. Lokasi untuk penelitian berada di Desa Raci Kulon Kecamatan Sidayu Kabupaten Gresik. Teknik pengumpulan data menggunakan beberapa langkah, meliputi: studi pustaka dan studi lapangan. Sumber data menggunakan person, place, paper. Analisis data menggunakan reduksi data, penyajian data, dan penarikan kesimpulan. Validitas data menggunakan triangulasi sumber, triangulasi teknik, dan triangulasi waktu.

\section{HASIL DAN PEMBAHASAN}

\section{Fungsi Kesenian Jaranan Jur Ngasinan Desa Sukorejo Kecamatan Sutojayan Kabupaten Blitar}

Jaranan Jur Ngasinan merupakan salah satu Jaranan yang tertua di Kabupaten Blitar (Wawancara, 4 Februari 2016). Awal munculnya pada tahun 1921 dengan nama Jaranan Ngasinan atau disebut Jaranan Tulungagung di Desa Sukorejo Kabupaten Blitar. Menurut Tamsir dahulu Sukorejo bernama Sukoanyar dan sebagian besar masyarakatnya merupakan pendatang yang berasal dari berbagai daerah salah satunya yaitu Tulungagung. Pada tahun 1921, didirikan kesenian Jaranan yang digunakan untuk melestarikan budaya Jawa (Wawancara, 1 April 2016). Fungsi Jaranan Jur Ngasinan antara lain:

\section{Sebagai Fungsi Ritual}

Jaranan Jur Ngasinan seni pertunjukan yang memiliki fungsi sebagai sarana ritual dengan ciri-ciri 1) pemilihan tempat yang terpilih dianggap sakral, misalnya di sekitar sanggar pusaka Gong Kyai Pradah, 2) pemilihan hari-hari tertentu misalnya pada bulan suro, 3) pemain terpilih, yaitu pemain Jaranan Jur Ngasinan yang sudah tua karena telah memiliki pengalaman lebih tentang kehidupan sehingga mengerti tata cara bersikap yang benar, pemain Jaranan Jur Ngasinan yang memegang rasa kejujuran yang tinggi, tidak melanggar aturan untuk tidak minum minuman keras dan berjudi, 4) adanya seperangkat sesaji yang disiapkan. Ciri-ciri tersebut sesuai dengan pendapat Soedarsono (2002: 126) tentang ciri-ciri khas seni pertunjukan ritual.

Fungsi ritual Jaranan Jur Ngasinan yaitu sebagai arak-arakan dalam Ritual Siraman Gong Kyai Pradah. Menurut Mbah Mardjuni sesepuh Jaranan Jur Ngasinan konon terdapat suatu legenda Lodoyo geger kehilangan pusaka Gong Kyai Pradah. Pada tahun 1949 Gong Kyai Pradah ditemukan di rumah Mbok Rondo Dadapan ketika menyuruh pembantunya untuk memanjat pohon kelapa dan memetik buah kelapa. Akan tetapi, buah kelapa tidak jatuh lurus kebawah melainkan ke kanan dan kekiri. Hal ini yang membuat penasaran pembantu dan melihat kebawah terdapat puncu dari pusaka Gong Kyai Pradah. Wedono dan para Demang mendengar berita tersebut, namun tak seorangpun yang dapat memindahkan. Mardjuni menambahkan bahwa terdapat salah satu tokoh masyarakat yang bermimpi Gong Kyai Pradah dapat di boyong ke sanggar pusaka dengan arak-arakan Jaranan Jujur. Pada akhirnya, Jaranan dari Desa Sukorejo yang dapat memboyong Gong Kyai Pradah dan menjadi arak-arakan sampai ke sanggar pusaka. Hingga saat ini Jaranan Jur Ngasinan menjadi salah satu bagian dari acara ritual Siraman Gong Kyai Pradah. Siraman Gong Kyai Pradah dilaksanakan setiap Hari Maulid Nabi dan Hari Raya Idul Fitri (Wawancara, 15 Oktober 2015). Ketika arak-arakan baris yang paling depan yaitu Singo Barong kemudian pemain jaranan sedangkan celeng, kiri'an dan thetek melek berlarian kejar-kejaran dan menggoda penonton (Observasi, 25 Desember 2015).

Jaranan Jur Ngasinan juga digunakan sebagai sarana ritual bersih desa di Desa Sukorejo yang dilakukan setiap tanggal 11 sabtu pahing atau 12 minggu pon pada bulan Selo. Kegiatan bersih desa dilakukan pada pagi hari dengan agenda arak-arakan seluruh kesenian di Desa Sukorejo yaitu jaranan, sholawatan, jidor dan karawitan keliling desa, kemudian pada malam hari menggelar pertunjukan Jaranan Jur Ngasinan. Menyambut bulan Suro menga- 
dakan pertunjukan Jaranan Jur Ngasinan di rumah ketua kesenian Pak Budi Santoso atau di rumah tukang gambuh Pak Miskan. Sebelum pertunjukan berlangsung diadakan slametan dengan anggota kesenian dan masyarakat sekitar untuk menyambut bulan Suro.

Jaranan Jur Ngasinan digunakan sebagai nadzar yang merupakan bagian dari keperacayaan masyarakat. Jaranan Jur Ngasinan digunakan sebagai media ungkapan rasa syukur kepada Tuhan Yang Maha Esa atas berlimpahnya rezeki dan diberi kesembuhan dari bebagai penyakit sehingga disebut dengan Jaranan ujar. Ketika terdapat salah satu masyarakat mengucapkan nadzar untuk mengadakan pertunjukan Jaranan Jur Ngasinan harus benar-benar dilaksanakan jika tidak akan terjadi sesuatu hal yang tidak diinginkan pada keluarga masyarakat yang mengucapkan nadzar. Nadzar merupakan sebuah janji yang harus dilakukan. (Wawancara, 01 April 2016).

Uraian tersebut mengungkapkan bahwa masyarakat khususnya Desa Sukorejo membutuhkan kehadiran kesenian Jaranan Jur Ngasinan dalam kehidupan. Oleh karena itu, Kesenian Jaranan Jur Ngasinan disebut dengan Jaranan "Sakral" karena memiliki beberapa fungsi ritual. Hingga saat ini Jaranan Jur Ngasinan memiliki fungsi sebagai sarana ritual yang melambangkan rasa syukur masyarakat pendukungnya kepada Tuhan Yang Maha Esa.

\section{Sebagai Presentasi Estetis}

Presentasi dapat diartikan sebagai penyajian sedangkan estetis dapat diartikan keindahan sehingga presentasi estetis yaitu suatu keindahan yang disajikan, sejalan dengan pendapat Soedarsono (2001: 170) fungsi seni pertunjukan sebagai persentasi estetis yaitu menghibur kepada penonton, bahwa pertunjukan harus dipresentasikan atau disajikan kepada penonton yang disebut art of presentation. Kesenian Jaranan Jur Ngasinan merupakan salah satu seni pertunjukan Indonesia yang menarik dan memiliki makna pada setiap pertunjukan. (Observasi, 26 Desember 2015 dan 28 Februari 2016).

Hal ini dapat dilihat pada pertunjukan kesenian Jaranan Jur Ngasinan di acara-acara besar yang diselenggarakan oleh Kabupaten Blitar antara lain, perayaan hari kemerdakaan Indonesia, menyambut tahun baru, dan hari jadi Kabupaten Blitar. Kesenian Jaranan Jur Ngasinan merupakan seni hiburan yang mampu memikat hati masyrakat Kabupaten Blitar terutama di Desa Sukorejo, karena memiliki bentuk penyajian yang sama dari awal munculnya pada tahun 1921 hingga saat ini yang menimbulkan suatu keindahan.

Menurut Hunter Mead dalam The Liang Gie (1996: 74-76) nilai estetis yaitu Sensous (ragam indrawi), Formal (ragam bentuk), Associative (ragam perserikatan). Nilai estetis pada Kesenian Jaranan Jur Ngasinan ragam indrawi ditinjau dari bentuk tari yaitu gerakan penari serta musik iringan yang digunakan. Ragam bentuk ditinjau dari ker- ampakan gerak penari. Ragam perserikat ditinjau dari isi atau makna yang terkandung dalam gerak yang tetap mengandung unsur nilai-nilai budaya. Tolak ukur keberhasilan sebuah pertunjukan dapat dilihat dari segi penikmat atau penontonnya (Murgiyanto, 200:47). Terbukti disetiap pementasaan yang dilakukan oleh kelompok Jaranan Jur Ngasinan masyarakat Desa Sukorejo mulai anak-anak hingga orang dewasa sangat antusias dan bersemangat untuk menyaksikan pertunjukan sampai selesai. (Observasi, 26 Desember 2015, 01 Januari 2016 dan 28 Februari 2016).

\section{Sebagai Pengilat Solidaritas Kelompok Masyarakat}

Sebagai pengikat solidaritas kelompok masyarakat terlihat pada kesenian Jaranan Jur Ngasinan Desa Sukorejo Kecamatan Sutojayan Kabupaten Blitar. Setiap akan melakukan pertunjukan kesenian Jaranan Jur Ngasinan selalu melakukan pertemuan dengan para anggota dan pengurus yang disebut arisan. Solidaritas dan komunikasi terjalin dengan masyarakat sekitar ketika pertunjukan kesenian Jaranan Jur Ngasinan akan berlangsung. Hal ini terbukti saling bergotong royong untuk menyiapkan berbagai kebutuhan dari memasang sound hingga menyiapkan macam-macam sajen.

\section{Sebagai Media Pelestari Budaya}

Sebagai media pelastarian budaya, menurut Jacobus (2006: 115) pelestarian sebagai kegiatan atau yang dilakukan secara terus menerus, terarah dan terpadu guna mewujudkan tujuan tertentu yang mencerminkan adanya sesuatu yang tetap dan abadi, bersifat dinamis, luwes dan selektif. Jaranan Jur Ngasinan merupakan produk seni pertunjukan tradisional yang mengandung nilai-nilai budaya masyarakat pendukungnya yang harus dilestarikan sehingga dapat mengenalkan kebudayaan kepada para generasi muda. Nilai-nilai budaya yag terkadung dalam kesenian Jaranan Jur Ngasinan yaitu dimulai dari kebiasaan para pemain yang tidak boleh minum minuman keras, harus jujur dalam setiap tindakannya kemudian kebiasaan gotong royong antar anggota dan masyarakat yang merupakan salah satu budaya masyarakat Indonesia untuk saling membantu. Nilai agama yang selalu diterapkan oleh para anggota dan masyarakat Desa Sukorejo mengadakan pengajian atau slametan. Selain itu, isi yang terkandung di dalam kesenian tersebut dipertahankan keaslian dengan sejarah yang menceritakan tentang cerita rakyat Jawa sehingga masyarakat di Era Modern masih mengingat cerita di zaman dahulu. Jaranan Jur Ngasinan pada tanggal 28 Desember 2012 mendapat penganuggrahan dari Dewan Kesenian Kabupaten Blitar sebagai "Karti Budaya 2012" dalam kategori Pengembang dan Pelestari Seni.

\section{Makna Simbolik Kesenian Jaranan Jur Ngasinan Desa Sukorejo Kecamatan Sutojayan Kabupaten Blitar}

Latar belakang kesenian Jaranan Ngasinan di Desa Sukorejo Kecamatan Sutojayan Kabupaten Blitar menurut Mardjuni memiliki keterkaitan dengan cerita rakyat ten- 
tang Dewi Sekartaji putra Ratu Lembu Amilahur dari Keraton Jenggolo yang melarikan diri sampai ke Dhadapan karena terdapat konflik dengan saudara tirinya. Dewi Sekartaji merupakan kekasih dari Panji Asmoro Bangun. Di Dhadapan Dewi Sekartaji bertemu dan dirawat oleh Mbok Rondo Dhadapan. Suatu ketika Ratu Lembu Amiluhur merindukan Dewi Sekartaji dan memanggil Patih untuk mengumpulkan para prajurit Jenggolo yang sudah ahli dalam menunggang kuda ditugaskan mencari putrinya. Ketika dalam perjalanan yang bertepatan dengan musim kemarau para prajurit mulai kehabisan makanan dan pada saat itu bertemu dengan perampok dari hutan. Perampok tersebut ingin mengambil candangan makanan dan akan merampok ke rumah penduduk, kemudian terjadilah pertarungan. Prajurit mengalahkan perampok kemudian meneruskan perjalanan sedangkan perampok kembali ke dalam hutan. Pada suatu hari, Kolo Srenggi beristirahat di bawah pohon kamboja bermimpi bertemu wanita yang sangat cantik yaitu Dewi Sekartaji, kemudian Kolo Srenggi menjelma menjadi Dadung Kawok (ratu celeng). Ratu celeng melihat prajurit seperti melihat Dewi Sekartaji yang sangat cantik dan menggandrungi para prajurit penunggang kuda terjadilah peperangan antara celeng dan kiri'an. Prajurit kembali ke Jenggolo tanpa membawa Dewi Sekartaji, pada akhirnya Ratu mengadakan sayembara yang dapat menemukan putrinya akan diberi tanah kerajaan Jenggolo sesigar semongko (Wawancara, 15 Oktober 2015).

Jaranan Jur Ngasinan memiliki makna simbolik baik dalam pembabakan, gerak, musik, tata busana, property, pola lantai dan sesaji yang memiliki maksud dalam setiap pertunjukannya untuk disampaikan kepada penonton yaitu tentang cerita prajurit kuda dari Jenggolo yang mencari Dewi Sekartaji. Selain itu, menurut Budi Santoso dalam nama juga memiliki arti tersendiri (Wawancara, 01 April 2016). Uraian tersebut sesuai dengan pendapat tentang bentuk penyajian sebuah pertunjukan seni selalu mempunyai makna simbolis baik dari segi gerak, musik, tata rias busana, perlengkapan, dan property. Seperti yang diungkapkan oleh Jacqueline Smith (1985: 29), bahwa istilah penyajian adalah simbol-simbol atau tanda dalam suatu pentas.

\section{Jaranan "Jur" Ngasinan}

Jaranan Jur Ngasinan pada awalnya bernama "Jaranan Ngasinan" karena sesuai dengan nama salah satu daerah di Desa Sukorejo yang merupakan tempat munculnya kesenian ini. Daerah tersebut ketika musim kemarau panjang merupakan satu-satunya yang memiliki sumber air dari sebuah sumur dengan jenis air asin sehingga disebut daerah Ngasinan. Kini Desa Ngasinan berganti nama menjadi Desa Pulerejo, meskipun telah berganti nama tetapi jaranan asal Sukorejo tersebut tetap menggunakan nama "Jaranan Ngasinan" karena menjadi identitas yang tidak bisa ditinggalkan. Pada tahun 1949 nama Jaranan Ngasinan berganti menjadi "Jaranan Jur Ngasinan”. Asal mula dari cerita rakyat tentang ditemukannya Gong Kyai Pradah yang telah menghilang dan dapat dipindahkan ke Sanggar Pusaka menggunakan arak-arakan Jaranan Jujur. Pada saat itu Jaranan yang menjadi pengiring adalah Jaranan Ngasinan dari Sukorejo (Wawancara, 01 April 2016).

Kata "Jur" memiliki arti Jujur sehingga baik dalam pertunjukan dan pemainnya harus memiliki sifat jujur. Selain itu, dengan nama "Jur" menjadi tanda bahwa pemain jaranan tidak diperboleh untuk meminum minuman keras, bermain judi dan dianjurkan menjunjung tinggi kejujuran sehingga kesakralan kesenian Jaranan terjaga. Jika ada yang melanggar akan mendapat teguran berupa peringatan secara lisan bahkan dikeluarkan dari kesenian tersebut dan juga mendapat sanksi moril dari masyarakat sekitar berupa terkucilkan sehingga memunculkan sifat jera (Wawancara, 01 April 2016).

Alur penyajian dalam Kesenian Jaranan Jur Ngasinan Jaranan Ngasinan di Desa Sukorejo Kecamatan Sutojayan Kabupaten Blitar menurut Mardjuni memiliki keterkaitan dengan cerita rakyat tentang Dewi Sekartaji putra Ratu Lembu Amilahur dari Keraton Jenggolo yang melarikan diri sampai ke Dhadapan karena terdapat konflik dengan saudara tirinya. Suatu ketika Ratu Lembu Amiluhur merindukan Dewi Sekartaji dan memanggil Patih untuk mengumpulkan para prajurit Jenggolo yang sudah ahli dalam menunggang kuda ditugaskan mencari putrinya. Jaranan Jur Ngasinan memiliki makna simbolik baik dalam pembabakan, gerak, musik, tata busana, property, pola lantai dan sesaji yang memiliki maksud dalam setiap pertunjukannya untuk disampaikan kepada penonton yaitu tentang cerita prajurit kuda dari Jenggolo yang mencari Dewi Sekartaji.

\section{Adegan 1 Tayungan}

Merupakan adegan dasar yang meceritakan tentang para prajurit berkuda dari Kerajaan Jenggolo sedang mencari Dewi Sekartaji. Adegan tayungan memiliki makna saling gotong royong dan saling membantu antar prajurit untuk mencari Dewi Sekartaji. Hal ini sesuai dengan kebiasaan masyarakat Desa Sukorejo untuk saling menolong antar warga (Observasi, 25 Desember 2015 dan 28 Februari 2016).

\section{Adegan 2 Perang}

Terdapat 2 penari yang melakukan peperangan karena Patih Tameng Gito memasuki Keraton tanpa permisi dengan tidak sopan dan membuat Patih Jenggolo. Adegan ini memiliki maksud tentang perangnya Patih Tameng Gito melawan Patih Jenggolo saling beradu kekuatan.

\section{Adegan 3 Jaranan Dua yang ke 2}

Memiliki maksud tentang rasa perdamaian Panji Inu Kertopati serta Panji Gunungsari yang berusaha untuk melerai peperangan antara Patih Tameng Gito dan Patih Jenggolo. Makna dari adegan ini sesuai dengan yang dit- 


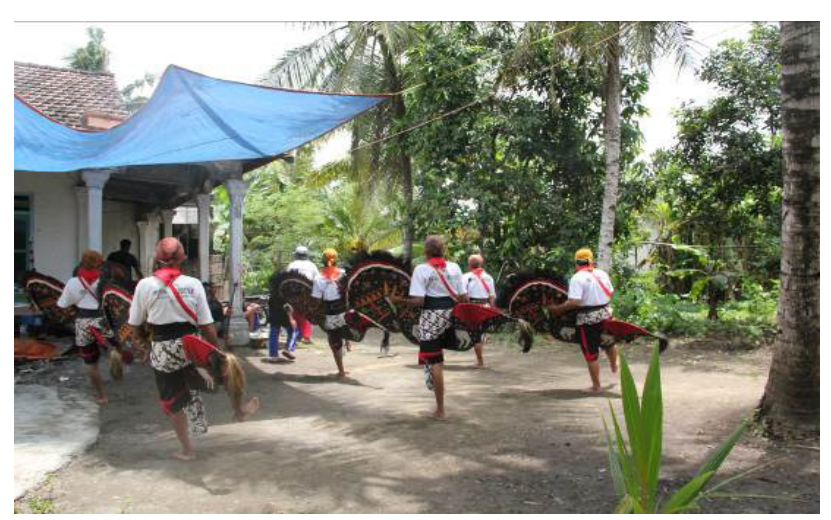

Gambar 1. Jaranan Jur Ngasinan

(Dok. Mufri Tgl 28 Februari 2016)

erapkan masyarakat Desa Sukorejo dalam keseraharian penuh dengan rasa perdamaian sehingga menimbulkan rasa solidaritas yang tinggi.

\section{Adegan Jejeran Singo Barong}

Memiliki makna kejahatan dan kelicikan singo barong tekalahkan dengan prajurit yang memegang teguh kejujuran. Sesuai dengan kehidupan bermasyarakt warga Desa Sukorejo yang menjunjung tinggi kebaikan serta kejujuran.

\section{Adegan Jejeran Jaranan Enam, Celengan, Kiri'an, dan Tetek Melek}

Memiliki maksud bahwa segala sesuatu yang berlebihan dari sifat Kolo Srenggi menimbulkan suatu masalah yang besar.

Setiap adegan dalam pertunjukan Jaranan Jur Ngasinan Desa Sukorejo Kecamatan Sutojayan Kabupaten terdapat pemain yang mengalami kerasukan. Kerasukan atau ndadi dikatakan oleh Holt pada tulisan Bambang Sugito dengan judul Seni Pertunjukan Jaranan Tulungagung dalam buku Cakrawala Seni Pertunjukan Indonesia sebagai berikut.

"Kerasukan adalah peristiwa dasar dari sebuah pertunjukan kuda kepang. Pada permulaan tari tampil teratur; dalam ritme-ritme yang regular dan ajeg yag dihasilkan oleh orkes perkusi kecil, pria berkuda itu 'berderap'dalam sebuah lingkaran. Pada beberapa pertunjukan mereka menjadi dua pihak yang terlibat dalm sebuah perkelaian pura-pura. Makin lama ritme-ritme yang menggoda menjadi lebih tegang dan lama sebelum seorang dari penari 'menjadi' (ndadi), yaitu kerasukan (Holt, 2000:127)".

Pemain jaranan ndadi dalam setiap pertujukan jaranan memiliki hubungan ritual dengan yang mempunyai hajat atau nadzar. Hubungan tersebut terkait dengan roh halus (leluhur) atau cikal bakal yang menjaga lingkungan masyarakat. Kerasukan atau ndadi merupakan media untuk menyampaikan sebuah pesan kepada orang memiliki hajat yang pertama tentang kelengkapan sesajen dan yang kedua mendo'akan agar selalu sehat, lancar, dan dilindungi oleh Tuhan Yang Maha Esa dalam kehidupannya (Wawancara, 20 April 2016).

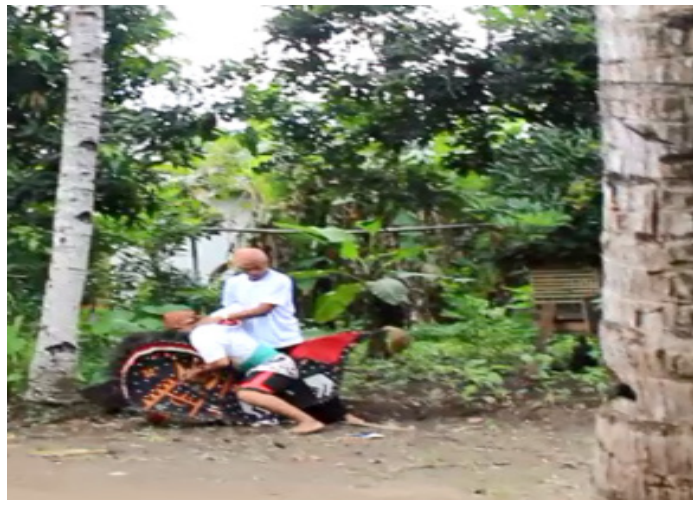

Gambar 2. Pemain Jaranan ndadi atau kerasukan (Dok. Mufri Tgl 28 Februari 2016)

Makna Gerak dalam Kesenian Jaranan Jur Ngasinan Bukak Kalangan (Persiapan menari)

Bukak kalangan atau disebut dengan persiapan menari dalam merupakan persiapan. Bukak kalangan memiliki maksud prajurit memohon perlindungan kepada Tuhan Yang Maha Esa agar diberi perlindungan dalam perjalanan mencari Dewi Sekartaji.

\section{Pacak Gulu (Liukan Leher)}

Gerakan Pacak Gulu atau gerak liukan leher banyak digunakan dalam tari tradisional. Pacak gulu memiliki makna prajurit melakukan persiapan yang matang untuk mencari Dewi Sekartaji.

\section{Nyirik (Seretan Kaki)}

Nyirik atau gerak seretan kaki merupakan gerak kaki diseret kesamping kanan atau kiri secara bergantian dengan posisi badan tidak berpindah tempat, gerak nyirik adalah gerakan yang sering dilakukan dalam kesenian Jaranan. Gerak nyirik memiliki makna prajurit menunggangi kuda dengan hati-hati agar semua prajurit selamat sampai tujuan.

\section{Singget (Penghubung)}

Singget adalah gerakan penghubung dengan gerakan lainnya. Memiliki makna penghubung perjalanan prajurit satu tempat dengan tempat yang lain dan prajurit siap dengan resiko yang akan dihadapi dalam melaksanakan tugasnya

\section{Junjungan (Angkatan Kaki)}

Gerak junjungan adalah gerakan angkatan kaki. Gerakjunjungan memiliki maksud kekuatan. Prajurit yang memiliki kekuatan pada dirinya dan selalu menghadapi rintangan tanpa rasa takut demi menemukan Dewi Sekartaji (Wawancara, 01 April 2016).

\section{Jalan Srimpet (Jalan silang)}

Gerak Jalan Srimpet atau jalan silang merupakan gerakan penari berjalan kesrimpet antara kaki kanan dan kaki kiri. Makna gerak jalan srimpet yaitu perjalanan prajurit yang penuh dengan rintangan ataupun cobaan untuk menemukan Dewi Sekartaji (Wawancara, 01 April 2016).

\section{Lenggang (Berjalan)}

Lenggang merupakan gerakan berjalan tanpa aturan. Memiliki makna tentang perjalan Prajurit mencari Dewi Sekartaji yang terus berjalan tanpa merasa letih dan tidak menyerah. Hal ini sesuai dengan kehidupan sehari-hari 
masyarakat Desa Sukorejo dalam melaksanakan pekerjaannya dari pagi hingga menjelang petang tanpa merasa letih untuk mendapatkan hasil yang memuaskan (Observasi, 28 Februari 2016).

\section{Gejugan (Hentakan tumit)}

Gejugan merupakan gerakan kaki yang selalu digunakan dalam setiap tari tradisonal terutama tari yang berunsur kebudayan Jawa. Gejug adalah gerakan menghentakkan kaki bagian telapak kaki kebelakang (tumit). Gerakan gejugan memiliki makna prajurit mengerjakan tugasnya penuh percaya diri.

\section{Loncatan}

Loncatan merupakan gerakan kaki yang penuh energi kaki digerakkan seperti melayang. Gerakan ini memiliki makna ketangkasan prajurit melawan rintangan-rintangan yang menghadang dalam perjalanan pencarian Dewi Sekartaji.

Jalan Nyirik

Jalan Nyirik gerakan berjalan kecil dengan cara diseret. Jalan nyirik dilakukan dengan kaki kanan dan kiri merapat lalu berjalan kedepan dengan kaki diseret sedikit-sedikit seperti gerak berjalannya robot. Jalan nyirik memiliki maksud tentang prajurit melakukan pencarian Dewi Sekartaji tanpa putus asa dengan menunggang kuda.

\section{Pacak Gulu Srimpet}

Pacak gulu srimpet merupakan gerakan gabungan dari gerakan leher dan gerakan kaki srimpet (silang). Pacak gulu srimpet melambangkan perjalanan prjurit yang penuh dengan kewaspadaan dan sangat berhati-hati.

\section{Lenggang Jaran (Kuda berjalan)}

Gerakan lenggang seperti yang telah dijelaskan yakni gerakan berjalan tanpa aturan. Gerakan ini memiliki makna tentang keperkasaan kuda yang digunakan oleh prajurit Jenggolo.

\section{Langkah Srimpet Jaranan}

Langkah srimpet jaranan merupakan gerakan dengan kaki berjalan silang bergantian antara kaki kanan dan kaki kiri. Langkah srimpet jaranan memiliki makna kegagahan prajurit menunggang kuda.

\section{Ngayun Jaran (Mengayun Kuda)}

Ngayun Jaran atau mengayuan kuda merupakan gerakan yang dilakukan berjalan dengan sedikit meloncat kecil seperti jalannya jaran ketika terkena pecut dari pemiliknya yang akan meloncat kemudian dengan gesit mulai untuk bergerak. Ngayun jaran memiliki makna kelihaian prajurit membawa kuda dan memberi arahan kemana kudanya harus bergerak

\section{Jaran Melayu}

Jaranan Melayu gerakan yang dilakukan seperti gerakan jaran yang berlari dengan kencang tidak perduli apapun yang ada didepannya dia tidak akan berhenti jika pemiliknya tidak memberikan aba-aba untuk berhenti. Jaran melayu memiliki makna prajurit yang penuh semangat dalam melakukan pencarian.

Makna Musik dalam Kesenian Jaranan Jur Ngasinan Instrumen yang digunakan dalam pertunjukan kesenian Jaranan Jur Ngasinan adalah kendang, slompret, angklung, angkrik, kencrong, kenong dan kempul. Selain beberapa instrument tersebut Jaranan Jur Ngasinan diiringi oleh vokal. Iringan vokal tersebut memiliki makna tentang identitas Jaranan Jur Ngasinan untuk diperkenalkan kepada para penonton sebagai pembukaan dalam pertunjukan Jaranan Jur Ngasinan. Selain itu, memiliki makna mengenalkan kebudayaan dan kesenian Jawa khususnya kesenian dari Kabupaten Blitar yang merupakan peninggalan para wali.

\section{Makna Tata Busana dalam Kesenian Jaranan Jur Ngasinan \\ Udeng Coklat dan Hitam}

Udeng atau iket merupakan hiasan yang dikenakan di kepala berbentuk segitiga dan terdapat corak batik. Udeng coklat digunakan oleh pemain Jaranan melambangkan identitas prajurit yang matang akan berfikir karena setiap perbuatan akan ada akibatnya. Melaksanakan tugas sesuai dengan ketentuan.

\section{Selempang Merah Putih dan Sapu Tangan Merah}

Memiliki makna identitas bangsa Indonesia sehingga menjadi tanda bahwa Jaranan merupakan kesenian asli yang dimiliki bangsa Indonesia. Kain merah berbentuk segita melambangkan keberanian prajurit dalam melwan apapun yang akan menyerang tanpa merasa takut sedikitpun.

\section{Sabuk atau Kendhit dan Stagen}

Sabuk sebagai salah satu perlengkapan wajib prajurit dalam berbusana pengendali nafsu sehingga prajurit dapat melaksanakan tugasnya dengan baik. Stagen melambangkan keperksaan prajurit yang dapat menahan angkara dan nafsu dalam menghadapi kehidupan.

Celana Panji Hitam dan Celana Panjang Motif Merah Celana panji hitam memiliki makna seragam keprajurit Keraton jaman dulu. Warna hitam melambangkan keperkasaan prajurit dan pita merah adalah dalam setiap langkahnya memiliki keberanian. Celana panjang motif merah melambangkan keperkasaan dan kekuatan.

\section{Jarik Parang Barong}

Jarik parang barong melambangkan orang Jawa yang penuh dengan kesederhanaan dan gagah berani, sedangkat warna putih adalah kesucian.

\section{Tata Busana Tukang Gambuh}

Tukang gambuh selalu menggunakan busana khas Jawa dan dilengkapi memakai blangkon coklat. Busana tersebut memiliki makna bahwa kesenian Jaranan merupakan kesenian asli masyarakat Jawa.

\section{Makna Properti dalam Kesenian Jaranan Jur Ngasinan \\ Properti Kuda}

Melambangkan kuda yang ditunggangi oleh para prajurit dari Jenggolo. Warna hitam melambangkan kekuatan kuda yang ditunggangi tidak terkalahkan. Warna kuning motif merah melambangkan semangat yang tidak pernah padam. Warna putih melambangkan suatu kesucian sesuai dengan julukan Jaranan Jur Ngasinan sebagai jaranan sakral yaitu apapun yang berkaitan dengan kesenian tersebut harus suci 


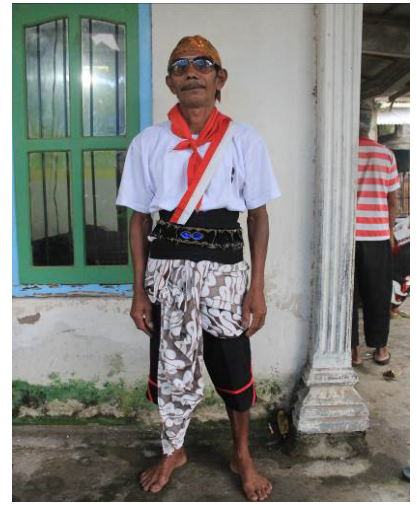

Gambar 3. Tata busana penari Jaranan (Dok. Mufri Tgl 28 Februari 2016)

dan sakral. Kain merah dan putih melambangkan identitas dan kemerdekaan bangsa Indonesia. Sapu tangan merah melambangkan keberanian dalam melawan apapun yang menghadang (Wawancara, 01 April 2016).

Properti Singo Barong

Menggambarkan tentang kejahatan yang dapat dilakukan dengan cara apapun terutama untuk memenuhi kebutuhan hidupnya dan melambangkan keserakahan.

\section{Celeng}

Merupakan babi hutan yang ganas dan rakus ditandai dengan warna hitam yang merupakan lambang kekuatan.

\section{Kiri'an}

Memiliki warna hitam dan putih melambangkan kekuatan dan kesucian melindungi prajurit jaranan dari serangan celeng. Topeng dengan warna merah, bermata besar dan berkumis tipis melambangkan pemilik kiri'an yang gagah berani dan senang menggoda prajurit jaran dengan tingkah polanya (Wawancara, 01 April 2016).

\section{Thetek Melek}

Menggunakan topeng karena memiliki wajah yang buruk namun memiliki hati yang baik. Pecut memiliki makna sebagai kekuatan dalam pertunjukan ini. Kekuatan yang dimaksud yakni agar jaranan yang di tunggangi oleh prajurit dapat melaju dengan cepat tanpa lelah. Selain pecut yang digunakan penari ada pecut yang berada di bagian sesaji dan biasanya digunakan oleh tukang gambuh untuk mengusir energi negatif

\section{Makna Pola Lantai dalam Kesenian Jaranan Jur Ngasinan}

Pola lantai adalah posisi dan garis lantai yang akan dilalui oleh penari. Posisi penari dalam lantai ruang akan memberi kesan bobot dramatik adegan, suasana dan karakter kesan (seperti pantang menyerah, takut, bahagia) di samping jika sebagai bentuk estetik komposisi ruang.

Tabel 1. Pola Lantai Jaranan Jur Ngasinan dan Makna

\begin{tabular}{ll}
\hline No. Pola Lantai & Makna \\
\hline 1 & $\begin{array}{l}\text { Melambangkan } \\
\text { persiapan untuk } \\
\text { berangkat mencari } \\
\text { Dewi Sekartaji } \\
\text { agar terhindar dari } \\
\text { mara bahaya. }\end{array}$ \\
\end{tabular}

2

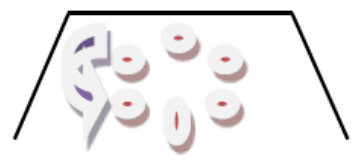

Melambangkan saling kerjasama antar prajurit dari awal pemberangkatan sampai akhir.

3

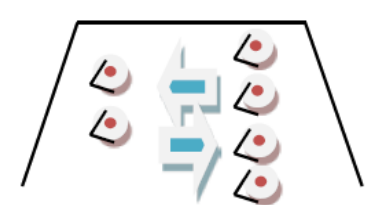

Melambangkan 2 orang sebagai pemimpin dan 4 orang sebagai prajurit.

4

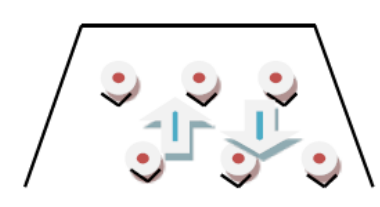

Melambangkan barisan prajurit untuk melawan huru-hara.

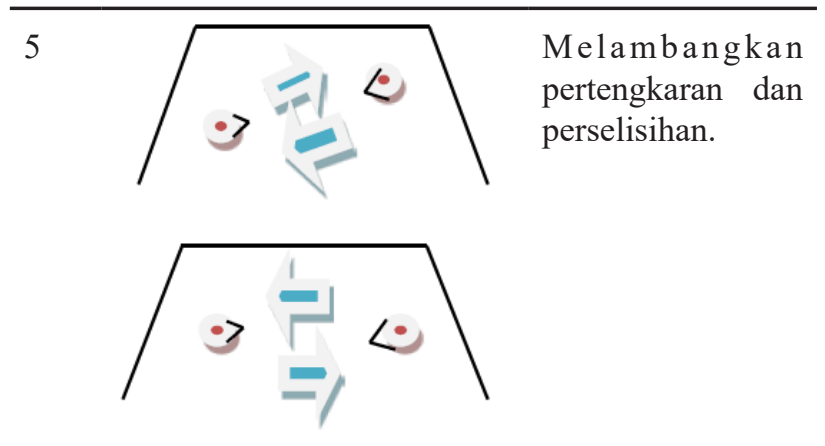

Keterangan :

$$
\begin{aligned}
& =\text { Tukang Gambuh } \\
& =\text { Pemain Jaranan } \\
& =\text { Arah Hadap }
\end{aligned}
$$

Makna Sesaji dalam Kesenian Jaranan Jur Ngasinan Sesaji merupakan salah satu sarana upacara yang tidak bisa ditinggalkan, dan disebut juga dengan sesajen yang dihaturkan pada saat-saat tertentu dalam rangka 
kepercayaam terhadap makhluk halus, yang berada ditempat-tempat tertentu. Sesaji merupakan jamuan dari berbagai macam sarana seperti bunga, kemenyan, uang recehan, makanan, yang dimaksudkn agar roh-roh tidak mengganggu dan mendapatkan keselamatan (Koentjaraningrat, 2002: 349). Sesaji merupakan sarana dan persyaratan yang sangat penting bahkan wajib dalam pelaksanaan pertunjukan kesenian Jaranan Jur Ngasinan. Sesaji dalam pertunjukan Jaranan Jur Ngasinan antara lain:

\section{Pisang Raja 2 sisir}

Pisang Raja merupakan jenis pisang yang besar dan terkenal dengan kemanisanya. Pisang Raja yang digunakan pada pertunjukanan Jaranan Jur Ngasinan berjumlah 2 sisir atau setangkep. Menggunakan 2 sisir memiliki makna bahwa dalam hidup tidak hanya sendiri namun membutuhkan oranglain. Sesajen menggunakan pisang Raja memiliki makna rasa kekeluargaan.

\section{Kelapa}

Kelapa diibaratkan sebagai sesuatu yang lengkap, karena dari segala aspek, kelapa dapa bermanfaat airnya, dagingnya, tempurungnya hingga sabutnya. Memiliki makna pemikiran yang jernih dan terbuka.

\section{Dawet}

Dawet memiliki isi yang banyak ketika disajikan dalam sesaji pertunjukan Jaranan Jur Ngasinan. Sehingga memiliki makna mendapatkan rezeki yang berlimpah.

\section{Rujak gobet}

Rujak gobet memiliki makna kuat dalam menjalani kehidupan, manusia dituntut untuk mampu menghadapi berbagai permasalahan dari Tuhan untuk mencapai suatu tujuan hal ini berkaitan dengan rasa rujak gobet pedas, manis dan asin seperti kehidupan.

Kendi kecil

Melambangkan hidup selalu dalam kesegaran karena kendi merupakan wadah untuk menyimpan air yang memiliki kesegeran (Tri Broto, 2009: 18).

\section{Kendi besar berisikan air}

Melambangkan dimurahkan rezeki berkaitan dengan bentuk kendi besar yang dapat menampung lebih bnyak air.

\section{Cok bakal}

Melambangkan dibuangnya kesialan pada diri manusia. Cok bakal memiliki wadah sendiri yang bernama takir, takir memiliki makna keblat papat limo pancer sesuai dengan bentuk takir yang memiliki 4 sudut dan 1 pusat di tengah. sesuai dengan bentuk takir yang memiliki 4 sudut dan 1 pusat di tengah. Keblat adalah arah mata angin yakni utara, selatan, timur dan barat. Empat arah mata angin memiliki simbol warna. Arah utara berwarna hitam bersifat lauwamah memiliki makna keserakahan. Arah selatan berwarna merah bersifat amarah. Arah barat berwarna kuning bersifat supiah memiliki makna kesenangan. Arah timur berwarna putih bersifat mutmainnah bermakna jujur (Sonya Kartika, 2007 33-35). Mengetahui keblat, seseorang akan mengetahui getaran ataupun zat yang ada Sisir dan kaca

Melambangkan dalam kehidupan manusia harus rapi baik kehidupan lahiriah ataupun duniawi.

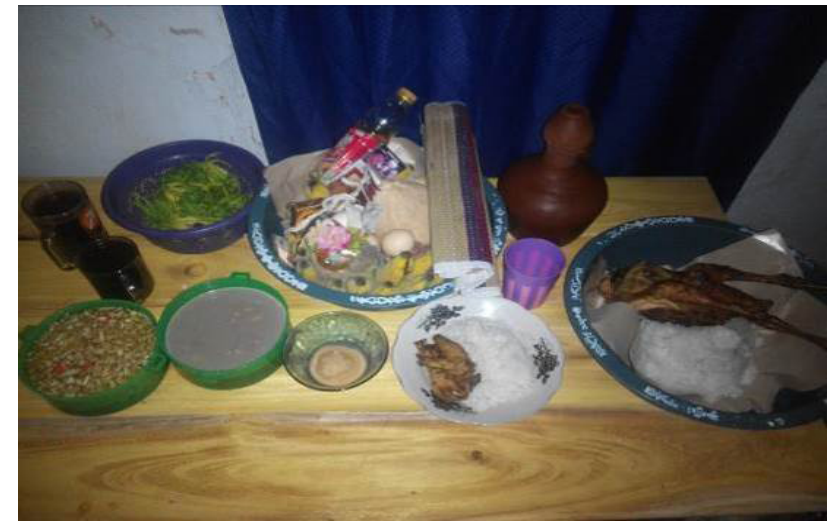

Gambar 4. Sesajen dalam pertunjukan Jaranan Jur Ngasinan (Dok. Mufri Tgl 26 Desember 2015)

\section{Lawe}

Lawe merupakan jenis benang yang terbuat dari kapas randu berwarna putih sebagai tali suci Melambangkan untuk orang yang memiliki nadzar segala urusannya dilancarkan seperti bentuk lawe yang memanjang dan tebal tidak mudah putus.

\section{Rokok klobot dan Kopi}

Melambangkan amongamong makanan dan minuman leluhur yaitu persebahan untuk leluhur.

Minyak wangi fanbo

Memiliki makna menyebar luaskan hal-hal yang baik menimbulkan keharuman.

\section{Kembang Kenongo}

Kembang kenongo merupakan kembang yang memiliki bau sangat khas, kembang ini biasanya digunakan dalam berbagai ritual mulai dari ritual seni pertunjukan sampai ritual pernikahan. Kembang kenongo melambangkan wewangian selain itu kembang kenongo memiliki lima daun bunga yang bermakna orang yang beragama islam tetap memegang rukun Islam

\section{Telur}

Merupakan simbol asal-muasalnya manusia.

\section{Kemenyan}

Melambangkan pengusiran roh-roh halus dan menjauhkan dari energi negatif.

\section{Parem}

Merupakan simbol penghormatan kepada roh leluhur. Bedak boreh menghilangkan sawan atau tolak sawan.

\section{Tikar}

Tikar adalah alat untuk alas tidur atau duduk yang terbuat dari hasil anyaman, tikar yang digunakan dalam pertunjukan Jaranan Jur Ngasinan berukuran kecil. Tikar diartikan sebagai dasar hukum kehidupan.

\section{Uang}

Digunakan dalam sesajen yang memiliki makna bahwa manusia harus ingat untuk selalu sedekah.

\section{Nasi Tumpeng}

Nasi tupeng atau disebut dengan Buceng merupakan nasi berbentuk kerucut. Melambangkan suatu cita-cita atau tujuan yang mulia ditunjukkan kepada Tuhan Yang Maha Esa. 


\section{Ayam panggang}

Ayam panggang yang dimasak secara utuh. Ayam panggang dalam sesajen juga simbol mensucikan yang punya hajat. Nasi tumpeng dan ayam panggang dalam pertunjukan Jaranan Jur Ngasinan dihidangkan menjadi satu yakni ayam panggang diletakkan diatas nasi tumpeng.

\section{Makna Do'a dalam Kesenian Jaranan Jur Ngasinan}

Menurut Miskan Juru Gambuh do'a yang digunakan dalam pertunjukan Jaranan Jur Ngasinan ada dua yakni pada saat sebelum pertunjukan dimulai dan saat digunakan untuk menyembuhkan atau menyadarkan pemain jaranan yang trance. Memiliki makna meminta perlindungan dan keselamatan kepada Tuhan dan tidak lupa untuk meminta izin kepada leluhur untuk melaksanakan suatu kegiatan agar tidak terjadi sesuatu yang tidak diinginkan.

\section{SIMPULAN}

Pertama, Kesenian Jaranan Jur Ngasinan memiliki beberapa fungsi yang berbeda dengan kesenian jaranan lainnya. Fungsi kesenian Jaranan Jur Ngasinan yaitu sebagai sarana ritual dalam Siraman Gong Kyai dan media ungkapan rasa syukur kepada Tuhan Yang Maha Esa. Sebagai presentasi estetis pertunjukan kesenian Jaranan Jur Ngasinan digunakan dalam acara-acara besar yang diselenggarakan oleh Kabupaten Blitar. Sebagai pengikat solidaritas kelompok masyarakat, dan sebagai media pelestarai budaya. Jaranan Jur Ngasinan merupakan produk seni pertunjukan tradisional yang mengandung nilai-nilai budaya masyarakat pendukungnya yang harus dilestarikan sehingga dapat mengenalkan kebudayaan kepada para generasi muda.

Kedua, Kesenian Jaranan Jur Ngasinan Desa Sukorejo Kecamatan Sutojayan Kabupaten Blitar memiliki makna simbolik baik dalam pembabakan yang terbagi dalam 5 babak gerak yang memilik makna prajuri gagah berani. Iringan vokal yang memiliki makna simbolik tentang kesenian Jawa yang ada di Kabupaten Blitar. Tata busana yang dikenakan memiliki makna simbolik baju atau seragam keprajuritan terdiri dari beberapa warna yakni merah memiliki maksud keberanian, hitam bermaknan keganasan dan putih adalah kesucian. Properti terdiri dari kuda, replika celeng, replika kiri'a, singo barong, topeng thetek melek dan pecut. Pola lantai yang memiliki maksud dalam setiap pertunjukannya untuk disampaikan kepada penonton yaitu perjalanan prajurit. Setiap pertunjukan berlangsung selau terdapat Sesaji dan di dahului dengan do'a memiliki makna yang berkaitan dengan kepercayaan masyarakat sekitar untuk mengucap syukur kepada Tuhan atas keberkahan dan keselamatan dalam kehidupan hingga saat ini. Dalam makna simbolik yang terdapat pada kesenian Jaranan Jur Ngasinan memiliki kaitan dengan nilai-nilai budaya masyarakat Desa Sukorejo.

\section{DAFTAR RUJUKAN}

Bastomi, Suwaji (1992). Seni Dan Budaya. Semaranag: IKIP Semarang Press.

Creswell, John W (2010). Research Design Pendekatan Kualitatif, Kuantitatif, dan Mixed. Yogyakarta: Pustaka Pelajar

(2013). Reserch Dsign: Pendekatan Kualitatif, Kuantitatif, dan Mixed. Yogyakarta: Pustaka Pelajar

(2015). Penelitian Kualitatif dan Desain

Riset. Yogyakarta: Pustaka Pelajar

Darsono, Sonya Kartika (2007). Budaya Nusantara. Bandung: Rekayasa Sains

Giri, Wahyana (2010). Sajen dan Ritual Orang Jawa. Yogyakarta: Narasi

Hadi, Sumandiyo (2007). Kajian Tari Teks Dan Konteks. Yogyakarta: Pustaka Book Publisher.

Hidayat, Robby dan R. Djoko Prakoso. 2008. Seni Pertunjukan Etnik Jawa Ritus, Simbolisme, Politik, dan Problematikanya. Malang: Gantar Gumelar

Humardani (1985). Kumpulan Kertas Tentang Kesenian. Surakarta: Proyek ASTI

K. Langer, Sussane (1998). Problem of Art: Ten Philosophical Lectures. Diterjemahkan Oleh Widaryanto. Bandung: ASTI

Kasmahidayat, Yuliawan (2012). Apresiasi Symbol Dalam Seni Nusantara. Cv. Bintang WarliArtika

Kusmayati, Hermien (1998). Rokat Bangkalan. Bandung: Sastrataya Masyarakat Seni Pertunjukan

Murgiyanto, Sal (1983). Koreografi Pengetahuan Dasar Komposisi Tari. Jakarta: Departemen Pendidikan Dan Kebudayaan

(2002). Kritik Tari : Bekal Kemampuan Dasar. Jakarta: Mayarakat SEni Pertunjukan Indonesia

Nuraini, Indah (2011). Tata Rias \& Busana Wayang Orang Gaya Surakarta. Yogyakarta: ISI Yogyakarta

(1993). Koreografi. Jakarta: Dekdibud

Pigeud. (1983). Pertunjukan Rakyat Jawa. Terjemahan Muhammad Husodo Pironggokusumo. 1991. Surakarta:Perpustakaan Reksa Pustaka 
Prakoso, Djoko (2006). "Kesenian Jaranan Kota Surabaya Studi Tentang Fungsi Kesenian Dalam Kehidupan Warga Musiman”. TESIS tidak diterbitkan. Surakarta: Pasca Sarjana STSI

Sedyawati, Edi (2002). Indonesia Heritage (Seni Pertunjukan). Jakarta: Buku Antar Bangsa

Smith, Jacqueline (1985). Komposisi Tari: Sebuah Petunjuk Praktis Bagi Guru, Terjemahan Ben Soeharto. Yogyakarta: Ikalasti

Soedarsono (1993). Tari-Tarian Indonesia I. Jakarta: Departemen Pendidikan \& Kebudayaan

(2001). Metodologi Penelitian Seni Pertunjukan Rupa.. Yogyakarta: Masyarakat Seni Pertunjukan Indonesia

(2002). Seni Pertunjukan Di Era Globalisasi. Gadjahmada University Press.

The Lian Gie (1983). Garis Besar Estetika (Filsafat Keindahan). Yogyakarta: Super Sukses

Wahyuni, Eko dkk (2009). Koreografi Etnik Jawa Timur. Surabaya: DK Jatim 